\title{
Production of Composite Materials By the Powder Metallurgy Method from the Powder Manufactured from Wastes of Mechanical Treatment of Ingots of Alloys VT-22
}

\section{Olga Vladimirovna Romanova, Olga Fedorovna Rybalko, Mikhail Nikolaevich} Zakharov, and Nina losifovna Ilinykh

Institute of Metallurgy of the Ural Branch of the Russian Academy of Sciences 101, Amundsen street, Ekaterinburg, Russia

\section{Abstract}

This study considers the preparation of new composite materials based on VT-22 titanium alloy powder made from waste from machining ingots by plasma spraying. Two composite compositions were selected for the study: 1 - 65\% VT-22 + 30\% PTM-1 + 5\% N70Y30 and $2-70 \%$ VT-22 + 25\% PTM-1 + 5\% PMS. The structure and microstructure of the samples were studied, and X-ray phase analysis was carried out. Materials with

Corresponding Author: Olga Vladimirovna Romanova pridlize@mail.ru

Published: 31 December 2020 Publishing services provided by Knowledge E

(c) Olga Vladimirovna Romanova et al. This article is distributed under the terms of the Commons Attribution License, which permits unrestricted use and redistribution provided that the original author and source are credited.

Selection and Peer-review under the responsibility of the TECHNOGEN-2019 Conference Committee.

\section{G OPEN ACCESS}

Nowadays the new materials and resource-saving technologies have a big importance in the modern production. The titanium alloys have a special interest due to their unique properties [1, 2].

When the details are manufactured using the traditional technology, the initial materials are ingots of titanium and its alloys. In these cases the material utilization factor (MUF) from forgings is only 0.08, from the rod joints - 0.11-0.26. Wherein a significant amount of shavings and lump waste is formed, and their weight often exceeds the weight of finished products [3].

In our work, we consider the preparation of composite materials by powder metallurgy from a powder made from waste machining of VT-22 alloy ingots by plasma spraying of a metal electrode at Kompozit OJSC (Korolev, Moscow Region).

To study the morphology of the powders, a Carl Zeiss EVO 40 scanning electron microscope was used. Particle size, degree of sphericity, and degree of symmetry of the particles were determined on a CAMSIZER - XT instrument. The phase composition 
was determined using a D8 ADVANCE diffractometer (Bruker AXS, Germany). The study of the particle microstructure was carried out on the metallographic thin section using an Olympus GX-51 optical microscope (Japan).

All used devices belong to the collective management center "Rational Nature Management and Advanced Materials Technologies" "Ural-M".

Sintering was carried out on a experimental installation created at the Institute of Metallurgy of the Ural Branch of the Russian Academy of Sciences and intended for a high-temperature investigations of the processes of reduction in the atmosphere of a neutral gas or in a technical vacuum (10 Pa). The basis of this installation is a vacuum resistance furnace with a graphite heater.

To control the change in the mass of the crucible with the sample during the experiment, we used scales of our own design based on an electromechanical transducer of the type E-2D1.

The temperature and mass of the sample were recorded using the L-CARD data acquisition system. Due to the presence of two channels of a digital-to-analog converter (DAC), the system also made it possible to control the temperature of the furnace in real time according to a given program.

Particles of VT-22 powder fractions of less than 100 microns have a rounded and spherical shape: the average sphericity coefficient is 0.722 , the symmetry coefficient is 0.876, particles with subindividues are found (Figure 1).

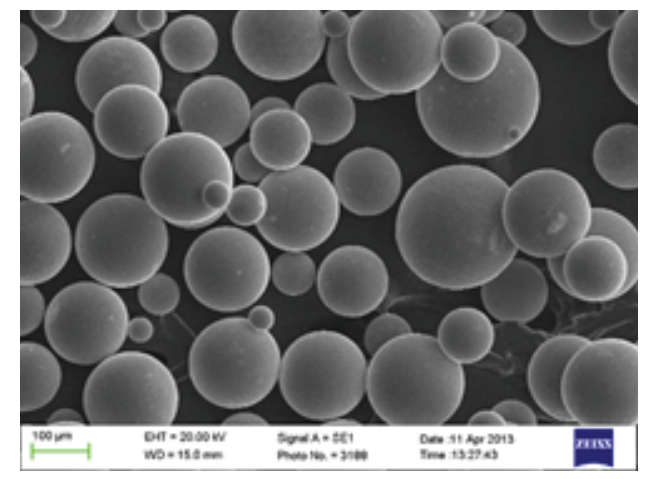

Figure 1: The morphology of the powder obtained from VT-22 alloy by plasma spraying, $\times 200$

Pressings made of VT-22 alloy powders crumble, particles deform, but do not adhere to each other. Therefore for the preparing of compacts from VT-22 alloy powders, it is necessary to use additional components with high ductility and facilitating the setting of solid particles among themselves as a binder. Achieving of the required mechanical properties of the workpieces is ensured by a uniform distribution of more ductile components [4-7]. 
Therefore additives of finer powders with particles with a developed surface were used: titanium obtained by the calcium hydride method, nickel by carbonyl method (PTM-1), nickel-aluminum alloys (N70Y30) - by reduction, copper - by electrolysis (PMS). The average particle size and bulk density of the powders are presented in the Table 1.

TABLE 1: Properties of additive powders

\begin{tabular}{|c|c|c|c|c|}
\hline Property & \multicolumn{4}{|c|}{ Powder grade } \\
\hline & PTM-1 & PNK-UTK & PMS-1 & PB-N70Y30 \\
\hline $\mathrm{C}_{v}, \mathrm{~g} / \mathrm{sm}^{3}$ & 1.08 & 2.37 & 1.72 & 2.67 \\
\hline $\mathrm{d}_{m}$, micron & 46.3 & 11.2 & 15.6 & 40 \\
\hline
\end{tabular}

It is shown, that the optimal content of VT-22 in the mixture should be in the range from $50 \%$ to $75 \%$. This paper presents investigations of two composite compositions:

1 - 65\% VT-22+30\% PTM -1+5\% N70Y30;

2 - 70\% VT-22+25\% PTM-1+5\% PMS.

Samples were pressed on an MS-500 press in a collapsible mold at a pressure of 350 $\mathrm{kN}$. The diameter of the obtained samples is $15 \mathrm{~mm}$. Samples were sintered in helium atmosphere. Heating was carried out to $900^{\circ} \mathrm{C}$ at a rate of 10 degrees per minute, then exposure was carried out for 4 hours and cooling with the oven to room temperature.

After sintering, sample 1 had a density of $4.2 \mathrm{~g} / \mathrm{cm} 3$, hardness $340 \mathrm{HB}$, sample 2 had a density of $4.3 \mathrm{~g} / \mathrm{cm} 3$, hardness $310 \mathrm{HB}$. The hardness of the pure alloy VT-22 according to reference data in the annealed state is $285 \mathrm{HB}$ [2].

Metallographic studies of the samples were carried out. For the study, thin sections were prepared from the surface of the tablets and a cross section of the obtained samples.

The study of the non-etched samples showed a uniform metal surface of the sintered materials, as well as the presence of small and medium pores evenly distributed over the thin section. Figure 2 a shows the distribution of pores in sample 1 with a cross section of a tablet and a metal defect-free surface of a thin section. Figure $2 \mathrm{~b}$ shows a homogeneous sintered metal structure with rare middle pores and a lot of small round or equiaxial ones. Comparison of the surfaces of sample 1 and 2 showed that in sample 2 there are more small point pores, especially in the middle part.

The etching was carried out using a standard etchant for titanium alloys. Sample 1 consists of a uniformly uniform equiaxed grain with a $\beta$-structure and precipitates of the $\alpha$-phase along the boundaries of $\beta$-grains (Figure 3a). In areas close to the surface of sample 1, light equiaxial inclusions of the $\alpha$-phase are observed, as well as groups of such inclusions (Figure 3b). Similar inclusions of the $\alpha$-phase are also found inside the thin section, but much less frequently and finer (Figure 3c). 


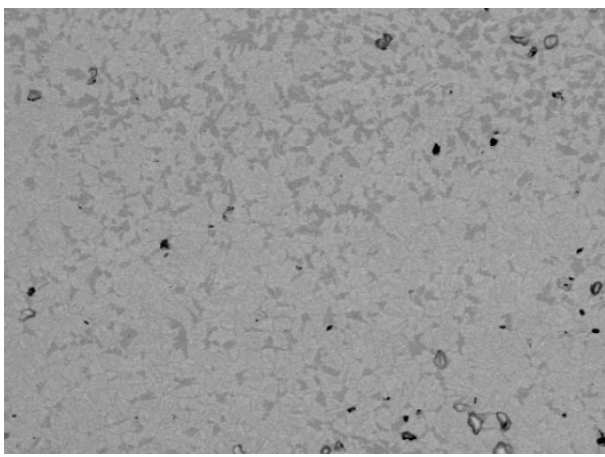

$\mathrm{a}$

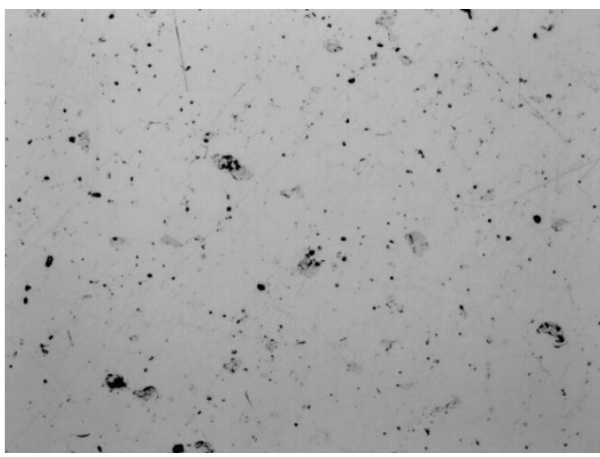

6

Figure 2: Metallographic thin section of sintered samples: a -sample 1, $\times 200, b-$ sample $2, \times 100$

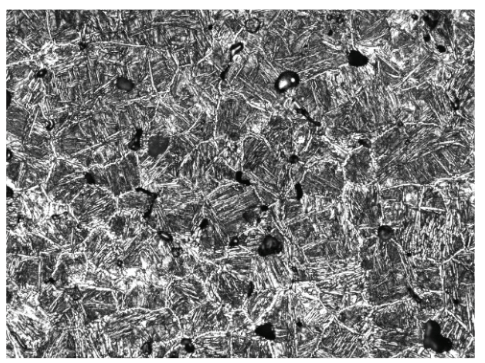

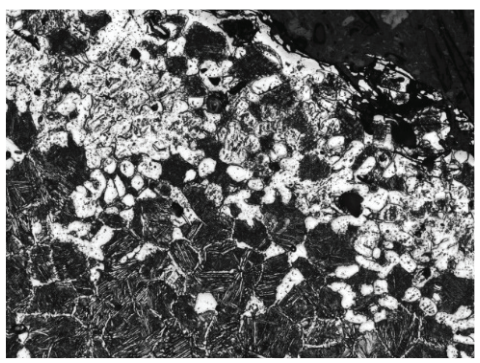

b

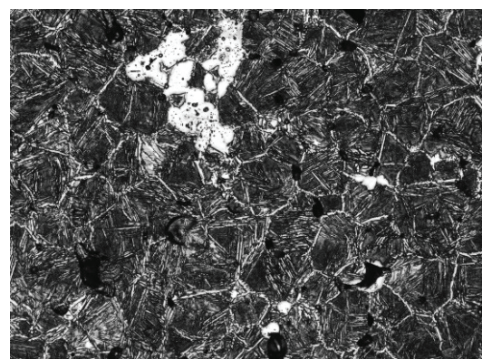

c

Figure 3: Microstructure of sample 1, $\times 200$

Sample 2 has a microstructure of $\alpha+\beta$ titanium (Figure 4a) and a nonuniform grain size (Figure 4b).

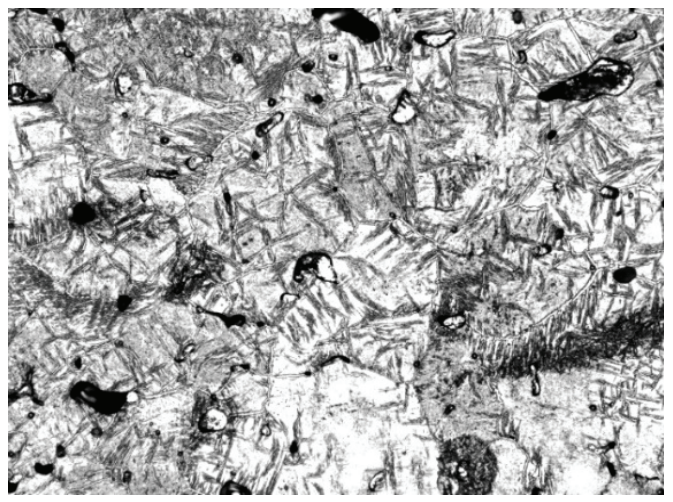

a

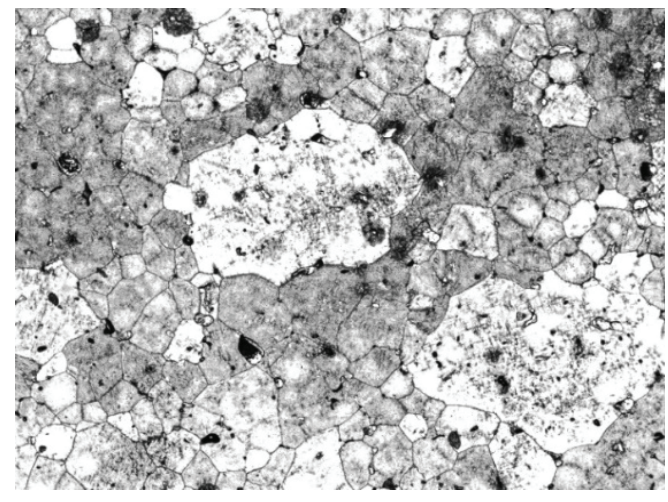

b

Figure 4: Microstructure of sample 2: $a-\times 200, b-\times 100$

Investigation of the structure and microstructure of the obtained samples shows that there was a complete sintering and homogenization of the powder materials with the formation of a single solid solution followed by cooling with the formation of $\alpha$ and $\beta$ phases. These facts can be explained by high pressing pressure and long exposure during sintering. 
The X-ray phase analysis of the samples showed the presence of $\alpha$ and $\beta$ phases of titanium, which confirms the data of metallographic studies.

There were obtained new materials with a homogeneous fine structure by cold pressing followed by sintering. The samples have the structure of the VT-22 alloy, but have a hardness higher than that of the initial material. In the future, it is planned to execute the mechanical tests of the materials obtained.

This work was financially supported by the Ural Branch of the Russian Academy of Sciences (grant No. 18-5-3-37), as well as under the State Assignment of the IMET UB RAS within the framework of the Program of Fundamental Research of State Academies, experiments were performed using the equipment of the Ural-M Central Scientific-Educational Center.

\section{References}

[1] Qian, M. and Froes, F. H. (Eds.). (2015). Titanium Powder Metallurgy: Science, Technology and Applications. United Kingdom, Elsevier Butterworth-Heinemann.

[2] Il'in, A. A., Kolachev, I. S. and Polkin, I. S. (2009). Titanium Alloys. Composition, Structure, Properties. Directory. Moscow: VILS-MATI.

[3] Alexandrov, A. A., et al. (2017). The Use of Metallurgy of Granules of Titanium Alloys to Obtain New Materials and Products with Enhanced Characteristics. Scientific and Technical Journal Titan, issue 1, vol. 55, pp. 28-33.

[4] Veiga, C., Davim, J. P. and Loureiro, A. J. R. (2012). Properties and Applications of Titanium Alloys: A Brief Review. Reviews on Advanced Materials Science, vol. 32, pp.133-148.

[5] Anciferova, I. V. (2004). Powder Titanium Materials. Vestnic OGU, issue 2, pp. 198202.

[6] Schennikova, T. L., et al. (2015). Investigation of the Properties of Powders of VT-22 Alloy and Powder Materials based on it. Perspectivnie materialy, issue 4, pp. 15-20.

[7] Robertson, I. M. and Schaffer, G. B. (2010). Review of Densification of Titanium based Powder Systems in Press and Sinter Processing. Powder Metallurgy, vol. 53, issue 2, pp. 146-162. 